\title{
Jean Jacques Dessalines. fundador de la nación haitiana
}

\author{
Johanna von Grafenstein Gareis
}

Jean Jacques Dessalines, el prócer que condujo a la nación haitiana a su independencia, integra, junto a su predecesor, Toussaint Louverture, sus lugartenientes y compañeros de armas, Henri Christophe y Alexandre Pétion, un núcleo de grandes capitanes y dirigentes políticos que protagonizaron la primera lucha de emancipación de nuestra América. Estos próceres son poco conocidos en el continente y al mencionar a los héroes de la lucha por la independencia de América Latina, se omite a menudo mencionarlos; de entre ellos, la figura de Jean Jacques Dessalines queda todavía más olvidada. Toussaint Louverture es sin duda el que tiene mayor proyección internacional porque emergió como lider en el periodo de enfrentamiento pero de no ruptura con Francia. La historiografía francesa - de la revolución de 1789 y del periodo Napoleónico - hace amplia referencia a este personaje que se enfrentó al poderoso imperio. Toussaint murió en Francia, después de haber sido traicionado y hecho prisionero por el general Leclerc, quien, como representante y cuñado de Napoleón, habia acordado su rendición.

Alexandre Pétion es ampliamente conocido en América Latina por la ayuda que dio al libertador Bolivar, ayuda en hombres, armas y dinero, que resultó ser importante para la segunda fase de la lucha por la independencia de Venezuela y América del Sur.

El Rey Henri Christophe ha dejado una imagen de gran monarca que es recordada por Alejo Carpentier, asi como por el poeta martiniquense Aimé Césaire en la obra teatral "La tragedia del Rey Christophe"; incluso algunas historietas que circulan en México rememoran la figura de este fascinante personaje.

Dessalines, tal vez el más grande, es el menos conocido a nivel internacional, y no por casualidad, sino por haber sido el jefe que.llevó al triunfo la revolución haitiana, tan cuestionada en su tiempo por los intereses de las potencias colonialistas y racistas de la época - Francia, Inglaterra, España, Estados Unidos - . Por su intransigencia jacobina, Dessalines tuvo pocos admiradores afuera que pudieran dar a conocer su obra y aun su figura.

Nada más representativo del odio que suscitó el libertador y fundador de la nación haitiana que el libro publicado en Nueva España por Juan López Cancelado, a escasos dos años del triunfo revolucionario en Haiti, "Vida de J. J. Dessalines" de Luis Dubroca, del cual la editorial Miguel Porrúa de México ha publicado una edición facsimilar en 1983. Este libro, por su violencia en contra del jefe negro, muestra cómo en la Nueva España y demás colonias ibéricas, en particular en Cuba y Santo Domingo, frente al mal ejemplo que representaba la Revolución de Haití, poderosas fuerzas se aplicaron a presentarla, lo mis- 
mo que a su lider máximo, como verdaderos bárbaros que atentaban contra la civilización y el orden colonial. ${ }^{1}$

También en la historiografía haịtiana Jean Jacques Dessalines constituye una de las figuras políticas más controvertidas. Condenado por unos con ciego desdén, reivindicado y defendido por otros con igual pasión. Dessalines ha suscitado numerosos escritos sobre su persona y su gobierno.

Constituyen las principales fuentes para el estudio de este personaje los tres historiadores haitianos, llamados los "clásicos", Beaubrun Ardouin, Thomas Madiou y Joseph Saint-Remy, así como los múltiples testimonios transmitidos por viajeros y otros observadores extranjeros que conocieron Haití a inicios del siglo $\mathrm{XIX}^{3}$. En la rica producción intelectual que floreció en Haití durante la segunda mitad del siglo pasado, encontramos diferentes tendencias respecto a la valorización de Dessalines. Su defensa o crítica están en esos años muy ligadas a la llamada "cuestión del color", así como al debate ideológico en el que participan los intelectuales haitianos de la época: o bien se defiende a Dessalines como líder negro cuyo autoritarismo se considera muy adecuado a las condiciones politicosociales de su momento (como por ejemplo Louis Joseph Janvier), o bien se le critica como tirano y enemigo del sector mulato (como Anténor Firmin, entre otros). En nuestro siglo, finalmente, ha aparecido gran número de estudios cuyo tema es la historia de Haití en su conjunto o más específicamente la revolución de independencia, que dedican algunas páginas al periodo gubernamental de Dessalines, pero, es necesario subrayar, existen pocos estudios monográficos al respecto ${ }^{4}$.

\section{a) El Libertador}

Según Thomas Madiou, ${ }^{5}$ Dessalines nació en 1758 en Grande Rivière du Nord, en la propiedad Cormiers, perteneciente al francés Duclos.

Como esclavo de plantación, se encontraba sometido a un régimen

1 Paul Verna, Pétion y Bolivar, Caracas, Ministerio de Educación, 1970; Luis Dubróca, Vida de J.J. Dessalines, Gefe de los negros de Santo Domingo, México, Juan López Cancelada Editor, facsimilar, Miguel Porrúa, 1983; José Luciano Franco, La revolución de Haití, la batalla para el dominio del Caribe y del Golfo de México, La Habana, Academia de Ciencias, 1966; Gérard Pierre-Charles, El pensamiento socio-político moderno en el Caribe, México, Fondo de Cultura Económica, 1985; Roger Dorsinville, Toussaint Louverture ou la vocation de la liberté, París, Julliard, 1965.

2 Beaubrun Ardouin, Etudes sur l'Histoire d'Haiti, 11 vols; Thomas Madiou, Histoire d'Haiti, 4 vols.; Joseph Saint-Rémy, Pétion et Haiti, 5 vols.

${ }^{3}$ Marcus Rainsford, An Historical Account of the Black Empire of Hayti, Londres, 1805; Charles Malo, Histoire de l'ile de Saint Domingue, 1819; James Barskett, History of the Island of St. Domingo, From its Discovery by Columbus to the Present Period, Londres 1818; William Woodis Harvey, Sketches of Haiti from the expulsion of the French to the Death of Christophe, Londres, 1827; James Franklin, The Present State of Hayti with Remarks on its Agriculture, Commerce, Laws, Religion, Finances and Population, Londres, 1828; Jonathan Brown, The History and Present Condition of Si. Domingo, Filadelfia, 1837,2 vols.

4 Tenemos conocimiento de cuatro estudios monográficos sobre Dessalines: Timoléon Brutus, L'homme d'Airain. Elude monographique sur Jean Jacques Dessalines, fondateur de la nation haitienne, Puerto Príncipe; N. A. Thédore, 1946; Ricardo Pattee, J. J. Dessalines, fundador de Haiti, La Habana, Molina y Cia, Muralla 55-57, 1936; Hénock Trouillot, Dessalines ou la tragédie post-coloniale, Puerto Príncipe, Panorama, 1966; Mats Lundahl, Defense and Distribution: Agricultural Policy in Haiti during the Reign of Jean Jacques Dessalines, 1804-1806, s.p.i.

' Citado por T. Brutus, op. cit., vol. 1, p. 32. 
de trabajo riguroso, acrecentado en su inhumanidad por el cruel trato infligido por el amo a los esclavos. A la edad de 33 años, alrededor de 1791, fue vendido a un "negro libre", llamado Dessalines, del cual toma el nombre. Trabajaba con él como obrero, probablemente como techador.

A diferencia de Toussaint Louverture, su predecesor como lider revolucionario, Dessalines era iletrado, pero provisto de una energía, fuerza de decisión y talento militar, realzados aún por sus más grandes críticos.

Su participación en la revolución de la colonia Saint-Domingue se remonta muy probablemente a los inicios del movimiento, ya que en 1794 había alcanzado el grado de jefe de batallón. En 1795 es nombrado por Madiou y Ardouin ${ }^{6}$ como uno de los líderes de las tropas al mando de Toussaint Louverture. Como tal interviene en la campaña contra los ingleses, expulsados del país en 1798. En 1799 obtiene el grado de general de brigada. Lucha del lado de Toussaint en la guerra civil (1799-1800), combatiendo a las fuerzas rigaudistas del Sur.

En 1801, Louverture se impone en el escenario de Saint-Domingue como el jefe incontestable con quien la metrópoli tiene que contar. Es nombrado gobernador general de la isla y a los pocos meses proclama su Constitución de 1801 , misma que Bonaparte identifica como un supremo atrevimiento del jefe negro y una virtual declaración de independencia; Napoleón arma una gigantesca expedición en contra de Louverture con el fin de recuperar la próspera colonia. Desembarcan veintitrés mil hombres al mando del general Leclerc, cuñado de Bonaparte. El jefe negro no puede resistir tal embestida. Después de meses de resistencia se tiene que rendir: Las tropas francesas vuelven a tomar el control colonial de la isla, arrestan y mandan a Francia a Louverture.

Después del aprisionamiento de Toussaint y el repliegue de las fuerzas insurreccionales, en junio de 1802 , Dessalines se integra, como la mayoría de los lideres insurgentes, a las fuerzas coloniales de Leclerc, pero en octubre del mismo año, conjuntamente con Clerveaux, Christophe, Pétion y Daut, pasa nuevamente al lado insurgente.

En la última fase de la lucha por la independencia, que se inicia entónces, Dessalines se perfila más y más como su líder principal, posición que es confirmada en el Congreso de Arcahaie en mayo de 1803, cuando los demás líderes se someten expresamente a su mando. En esa reunión de los principales jefes se consagra la unidad de las fuerzas revolucionarias, simbolizada por la creación de la bandera haitiana cuyos colores azul y rojo significan los elementos negro y mulato. Las constantes derrotas infligidas a los franceses a lo largo del verano de 1803 los obligan a replegarse a algunas pocas ciudades hasta que en noviembre cae su último bastión, el Cabo Francés. Dessalines dicta entonces un acta de capitulación en términos altamente benignos para los derrotados.

También la primera Declaración de Independencia, proclamada el 29 dè noviembre y firmada por Dessalines, Christophe y Clerveaux, está escrita en un tono conciliatorio. Invita a los propietarios franceses, dispuestos a renunciar a la esclavitud, a regresar a sus propiedades; lamenta que algunos propietarios "buenos y humanos" hayan sufrido posibles excesos, cometidos por combatientes insurgentes. Ambos do. cumentos son expresión de la magnanimidad que guió a los lideres victoriosos en su reacción, aun después de haberse visto enfrentados a una

- Ibidem, p. 73. 
de las más crueles expediciones enviadas en contra de una colonia rebelde.

La Proclamación de Independencia del $1^{\circ}$ de enero de 1804 , en cambio, está escrita en un tono muy distinto. La autoafirmación vigorosa del nuevo Estado, el odio a Francia y el rechazo a toda convivencia con sus ciudadanos la impregnan. La Proclamación, expresión violenta de la voluntad libertaria de un pueblo recién liberado de la esclavitud, está precedida-por la designación de Dessalines como gobernador general, realizada en los siguientes términos:

Los generales y jefes de los ejércitos de la isla de Haití... (declaran): En nombre de la libertad, en nombre de la Independencia, en nombre del pueblo, que ha hecho feliz, lo proclamamos Gobernador General vitalicio de Haití. Juramos obedecer ciegamente a las leyes emanadas de su autoridad, la única que réconoceremos. Le damos el derecho de hacer la paz, la guerra y de nombrar su sucesor. ${ }^{7}$

\section{b) En la dirección del Estado}

Dessalines queda asi instalado en la dirección del segundo Estado independiente del continente americano.

Las características de su poder están evidentemente marcadas por las circunstancias en las que obtuvo la soberanía nacional, así como por los sucesos que habian sacudido a Europa desde el inicio de la Revolución francesa. Después de 13 años de lucha armada, que en momentos alcanzó niveles de violencia inauditos, un pueblo de esclavos, dirigido por generales negros y mulatos, logra vencer al temible ejército francés y erigirse como nación. Este hecho era inédito en el ámbito internacional. Su impacto sobre el mundo occidental de la época es comparable, observa Rayford W. Logan, al efecto que causó la Revolución rusa en 1917.8. Un reconocimiento del joven Estado, dirigido por exesclavos, era impensable para las principales naciones esclavistas. ${ }^{9}$ Así, Haití sólo obtuvo su reconocimiento oficial en 1825, cuando se lo "concedió" Francia a cambio de una "indemnización" exorbitante de $150000 \mathrm{mi}$ llones de francos. El reconocimiento por parte de Estados Unidos se dio en 1862. Este aislamiento y el temor de un nuevo intento de Francia por recuperar su colonia más rica fueron otros factores que determinaron el carácter del gobierno dessaliniano.

El poder ejercido por Dessalines ha suscitado los más variados comentarios: los viajeros de principios del siglo XIX repiten en su mayoria la idea de que Dessalines, si bien excelente militar y estratega, no tenía cualidades de administrador y político. Encontramos esa idea también en Beaubrun Ardouin, quien opinaba:

La naturaleza lo había creado para conquistar y no para gobernar. No pudo comprender que su papel de revolucionario se había cum-

1 Tomado de Jean Baptiste Saint-Victor, Deux Concepts de l'Indépendance à SaintDomingue, Puerto Príncipe 1944, p. 280.

8 Rayford W. Logan, The Diplomatic Relations of the United States with Haiti, 17761891, Chapell Hill, The University of North Carolina Press, 1941, p. 152.

Ibidem. 
plido y que el de administrador y gobernante comenzaba después de la independencia. ${ }^{10}$

Dantès Bellegarde lamenta que se haya entregado a Dessalines la dirección del Estado como recompensa a sus victorias en el campo de batalla, acto que, según él, " hizo escuela en la historia política del país en detrimento de la calidad de la dirección política. Ricardo Pattee hace hincapié en el imperio totalmente personal y autoritario, ya que Dessalines no creó ninguna nobleza ni "permitió que hubiera ninguna forma de gobierno representativo". ${ }^{12}$

Paul Moral, refiriéndose al poder imperial, habla de una "pompa un poco bárbara, pero capaz de impresionar a las masas extenuadas." 13

Por otra parte, el interesante material en el que se basa el estudio de Hénock Trouillot sobre Dessalines, da a entender que el gobierno personalista no se limitaba a la persona del emperador en la época de Dessalines. Trouillot muestra, a través de las observaciones de coetáneos, que Dessalines aún se vio seriamente afectado en la ejecución de su política por el frecuente incumplimiento de sus órdenes. Intereses personales, contrarios a la política del emperador, corrupción y espiritu autonomista de los funcionarios civiles y militares eran frecuentes causas 'de esas dificultades. "Dessalines", dice Trouillot, "no conoció la ayuda de sus colaboradores, que eran en sus respectivos distritos igualmente poderosos que el emperador." 14 Incluso parece haber existido cierto aislamiento del jefe de Estado frente a los demás funcionarios civiles y líderes militares. En este sentido, Madiou criticaba la elección de Marchand, una plantación situada en el interior del país, como capital de la nación.

Este lugar estaba retirado en el fondo de los bosques, lejos de las grandes ciudades donde se agitan las pasiones políticas. ${ }^{15}$

Tadeusz Lepkowski califica el poder ejercido por Dessalines como despotismo militar y lo considera la salida lógica de la situación políticomilitar de $1803 .{ }^{16}$ Pensamos que, efectivamente, la confirmación de su liderazgo en calidad de gobernador general y el "sometimiento ciego" de sus compañeros de lucha pueden ser vistos como una prolongación de su dirección en las fuerzas militares durante la lucha armada. Haiti se encontraba virtualmente en pie de guerra, dada la real amenaza de una invasión francesa, y sólo podia existir bajo un gobierno militarizado. Las fuerzas armadas eran evaluadas entre 15 y 37 mil hombres ${ }^{17}$ y en todo el país se construían febrilmente obras de fortificación militar para hacer frente a un eventual retorno de los franceses.

En octubre de 1804, Dessalines fue coronado emperador con el nom-

${ }^{10}$ Citado por Eleazar Córdova Bello, La Independencia de Haiti y su influencia en Hispanoamérica, Instituto Panamericano de Geografia e Historia, Caracas, 1967, p. 113.

11 Dantès Bellegarde, Histoire du peuple haitien, 1492-1952, Puerto Príncipe, 1953, p. 108 .

12 Ricardo Pattee, Haití, pueblo afroantillano, Madrid, Ediciones Cultura Hispana, 1956, p. $11 \dot{6}$

13 Paul Moral, Le Paysan haitien, Paris, Maisonneuve, 1961, p. 27.

14 Hénock Trouillot, op.cit., p. 25.

15 Ibidem, p. 27.

16 Tadeusz Lepkowski, Haití, La Habana, Casa de las Américas, 1969, vol. 2, p. 29.

i) James Leyburn, El pueblo haitiano, Buenos Aires, Editorial Claridad, 1946, p. 51. 
bre de Jacques I, cambio en su estatus que reforzó aún más el caräcter personal de su poder. Sin embargo, significó al mismo tiempo un avance en la definición formal del nuevo Estado, ya que el título de gobernador general evocaba todavía la situación de una colonia, es decir, la existencia de un poder superior al nacional.

Finalmente, la elaboración de la Constitución imperial, proclamada el 16 de junio de 1805 , dio un marco jurídico más preciso al poder ejercido por Dessalines. El documento establecía la independencia y soberanía total del país; declaraba abolida la esclavitud; consagraba la "fraternidad" entre los ciudadanos (mulatos y negros) y la igualdad de derechos ante la ley; estableció la inviolabilidad de la propiedad privada; prohibió a todo blanco pisar el territorio haitiano en calidad de propietario; declaraba el poder uno e indivisible, atribuyendo al ejecutivo facultades legislativas y judiciales; el emperador era además jefe supremo del ejército; la corona era elegible y no hereditaria; se estipulaba la formación de un Consejo de Estado, sin especificarse sus funciones; se preveían finalmente tres ministerios (de Hacienda e Interior, Guerra y Marina y una Secretaria de Estado).

Un gran número de estudios juzga el gobierno de Dessalines haciendo hincapié en la personalidad de éste. Según esta visión, el carácter feroz e irascible del emperador, su falta de instrucción y arbitrariedad, su vanidad e inclinación hacia el derroche, serían los factores esenciales que determinaron su política y finalmente su caida. En este contexto se hace referencia a la matanza de blancos, ordenada por Dessalines en abril de 1804, en la que la casi totalidad de los residentes franceses blancos fueron pasados por las armas. Sólo se exceptuaban sacerdotes, médicos y algunos profesionistas, así como los ciudadanos polacos y alemanes que habian llegado con el ejército expedicionario de Leclerc pero que se habían mostrado favorables a la causa haitiana. Creemos que estos trágicos sucesos sólo fueron en segundo término expresión del carácter violento de Dessalines y que más bien deben ser vistos como producto de toda la violencia acumulada en dos siglos de dominación colonial francesa, durante los cuales los esclavos negros muchas veces habían sido víctimas de las crueldades más horrendas, cometidas por los colonos franceses y por el ejército de Leclerc y Rochambeau.

En la Proclamación, pronunciada el 28 de abril de 1804, Dessalines afirma la justeza de la exterminación de los franceses que habían permanecido en el país. Del texto trasciende la voluntad del jefe de Estado de intimidar a las fuerzas esclavistas de la época y de mostrarles que Haití no retrocedia ante ningún medio para afirmarse como Estado libre en el cual propietarios colonialistas y esclavistas no tenian cabida. Es difícil juzgar los efectos políticos de la matanza. Si bien ese cruel desenlace de la dominación colonial significaba una posición de fuerza, es dudoso que haya desempeñado un papel en la conservación de la independencia de Haití. C. L. R. James, por su parte, juzga la masacre como un acto profundamente impolítico:

La masacre de blancos fue una tragedia. No para los blancos... quienes habían sido bien tratados por Toussaint y reiniciaron sus cruel-dades cuando pudieron; ellos no merecían ni una lágrima ni una linea. Fue una tragedia para los negros y los mulatos. Como la matanza no reemplazaba una política, sólo era venganza; y la venganza no tiene nada que ver con la política. Los blancos ya no eran de temer; por ello esas masacres inútiles sólo servian para degradar y deshuma- 
nizar una población que apenas comenzaba a vivir como nación y que cargaba con un tan amargo pasado. ${ }^{18}$

\section{c) Politica agraria}

Un tema de gran trascendencia en el estudio de Dessalines es el de su política agraria. Se ha discutido mucho sobre los objetivos y alcances de la misma, pero existe consenso en que fueron los efectos de dicha politica los que llevaron al surgimiento de una fuerte oposición interna y al asesinato del emperador el 17 de octubre de 1806 .

Quisiéramos dar en este lugar, a manera de antecedentes, algunos datos sobre la propiedad colonial y los cambios que conoció a partir del estallido de la Revolución en 1791: a fines de la época colonial, las tierras ricas de Saint-Domingue estaban en manos de los colonos franceses y -en una tercera parte- de los libertos o gente de color, fruto de la mezcla racial que se dio a lo largo de la dominación colonial a pesar de los prejuicios prevalecientes. La huida masiva de esclavos de las plantaciones y su incorporación a las tropas revolucionarias, la abolición de facto de la esclavitud en agosto de 1793 y de jure en abril de 1794, así como el éxodo de numerosos propietarios franceses modificaron la posesión de la tierra y su explotación. Jefes militares negros se apoderaron de bellas plantaciones y los mulatos lograron afianzar su control sobre vastas extensiones de tierra, sobre todo en la provincia del Sur. Por otra parte, ante la huida masiva de labradores y la necesidad de mantener altos niveles de producción y de exportación, requeridos para financiar la guerra, Toussaint Louverture, como gobernador general, así como Sonthonax y Polvorel, comisarios de la República Francesa, implantaron un régimen de trabajo que obligaba a los cultivadores a trabajar en condiciones no muy diferentes de las anteriores.

Tomando en cuenta esos hechos, los pasos más importantes de la politica agraria llevada a cabo por Dessalines, nos parecen ser los siguientes:

- La exclusión de toda propiedad colonial en el país, la eliminación física de los últimos residentes franceses, la prohibición a todo blanco de poseer bienes inmuebles y la confiscación de las propiedades pertenecientes a los franceses, constituyen los elementos más importantes de esa medida.

- El control sobre las propiedades en manos de los antiguos libertos o mulatos. Estos se atribuian frecuentemente algún parentesco u otro vínculo con los antiguos propietarios para justificarse como herederos de las tierras abandonadas. Dessalines buscaba impedir que ese sector de la población se apoderara en forma exclusiva de las tierras, sobre todo en el Sur. Con el objetivo de descubrir falsos propietarios, Dessalines emitió dos decretos sobre la verificación de los títulos de propiedad (el 24 de julio de 1805 y el 1 de septiembre de 1806). Fue sobre todo el segundo decreto y su rigurosa puesta en práctica por Louis Balthazar Inginac en el sur del país, lo que provocó la abierta rebelión de los propietarios -o presuntos propietarios- mulatos de esa región. Estalló esta rebelión en Port-Salut el 8 de octubre y se expandió por

${ }^{18}$ C.L.R. James, Les Jacobins Noirs. Toussaint Louverture et la Révolution de SaintDomingue, París, Editions Caribéennes, 4. ed. 1983, p. 331. 
todo el distrito Sur; el 15 de octubre se le unieron las fuerzas del distrito Oeste con Alexandre Pétion al frente. ${ }^{19}$

- La creación de un vasto dominio territorial controlado por el Estado. A través de las confiscaciones, Dessalines logró incorporar al dominio del Estado entre el 60 y $90 \%$ de las tierras. Gran parte de las mismas fueron arrendadas a funcionarios civiles y militares y explotadas como grandes propiedades con base en el trabajo de los "labradores" (cultivateurs) que trabajaban en condiciones muy similares a las que habian instaurado Toussaint y Sonthonax. Recibían como remuneración un cuarto de la producción; no podian abandonar libremente la plantación a la cual estaban adscritos; eran sometidos a largas jornadas de trabajo y al control ejercido por capataces militares - según James Barskett realizaban 2/3 partes del trabajo rendido por los esclavos en tiempos de la colonia. ${ }^{20}$

La creación de los Dominios del Estado y sus objetivos constituyen un punto álgido en la discusión sobre la trascendencia sociopolítica de Dessalines.

¿Fue su objetivo realizar un reparto equitativo de las tierras entre las masas liberadas de la esclavitud, como creen algunos?

Los defensores de esa visión citan generalmente las siguientes palabras de Dessalines, transmitidas por Madiou:

Hemos hecho la guerra para los otros. Antes de la sublevación, los hombres de color, hijos de blancos, no recibian la herencia de sus padres. ¿Cómo es que después de haber expulsado a los colonos, sus hijos reclaman sus bienes? ¿Y los pobres negros cuyos padres están todavía en Africa no han de recibir nada? Atención, negros y mulatos: los bienes que hemos conquistado derramando nuestra sangre pertenecen a todos y quiero que sean repartidos con toda equidad. ${ }^{21}$

Así, Louis Joseph Janvier, en los años ochenta del siglo pasado, opinaba que "Dessalines quiso fundar la verdadera independencia del campesino convirtiéndolo en propietario de la tierra". ${ }^{22}$ Ricardo Pattee opina que la política agraria de Dessalines permitió al campesino instalarse y vivir hasta la fecha en pequeñas propiedades, donde es "dueño de la tierra que cultiva y donde la agricultura capitalista e industrializada no ha logrado nunca penetrar." ${ }^{23}$ Gérard Pierre-Charles escribe al respecto:

La tendencia fundamental de la política agraria de Dessalines fue satisfacer la necesidad de poner las riquezas agrarias, nacionalizadas, bajo el control de la Administración de los Dominios, a fin de enriquecer el patrimonio nacional del nuevo Estado, $y$ de hacer propietarios, al mismo tiempo, a los antiguos esclavos combatientes, mediante un reparto más equitativo de una parte de las propiedades coloniales...

Es cierto que Dessalines no pudo conseguir este reparto efectivo de las tierras a todos, pero si se considera la época en la cual fueron

19 Lepkowski, op.cit., vol. 2., p. 43.

20 Barskett, op.cit., London 1972, p. 324.

21 Gérard Pierre-Charles, La economia haitiana y su vía de desarrollo, México, Edición Cuadernos Americanos, 1965, p. 33.

22 Citado por Paul Moral, op.cit., p. 33.

23 Pattee, Haiti..., op.cit., p. 119. 
emitidas sus concepciones económicas, es preciso elogiar el genio intuitivo y práctico de este revolucionario. El papel asignado a la Administración de los Dominios era la forma más avanzada, concebible en la época de intervención del Estado en la vida económica. ${ }^{24}$

En oposición a los juicios anteriores acerca de la voluntad explícita de Dessalines de realizar una política agraria en beneficio de las masas rurales, encontramos otras opiniones que niegan dicho contenido. Tenemos por un lado el estudio de Paul Moral quien atribuye la creación del Patrimonio Nacional por Dessalines más a su política "antisudista", es decir, a su voluntad de debilitar a los propietarios mulatos del Sur que a "su voluntad de beneficiar a las grandes masas". Esas sufrian más bien bajo la "disciplina militar y despiadada" que reinaba en las plantaciones. El arrendamiento de grandes extensiones del Patrimonio Nacional a militares sería además, en opinión de ese autor, expresión del "caporalismo agrario" practicado por Dessalines. ${ }^{25}$

Para James Leyburn, las confiscaciones de las tierras reclamadas por los mulatos del Sur significaban un abierto ataque a la propiedad privada que privó a "los mejores elementos de la población" de la "única base de la riqueza y la.independencia que conocian". ${ }^{26}$

En su estudio, Tadeusz Lepkowski describe las dificiles condiciones de trabajo bajo las que laboraban los trabajadores de las plantaciones y analiza sus consecuencias sociales. ${ }^{27}$

Mats Lundahl finalmente, en su trabajo sobre la política agraria de Dessalines, defiende la siguiente tesis: la creación del Patrimonio Nacional fue determinada por la necesidad de garantizar altos ingresos estatales con el fin de mantener un ejército numeroso, ya que existia la real amenaza de un intento de reconquista por parte de Francia. ${ }^{28}$

Nos parece difícil juzgar la validez de las distintas opiniones expuestas en lo anterior ya que los datos existentes sobre el tema son muy escasos. Dada esa limitación informativa, la discusión obligadamente se basa en el mismo material que se cita y reinterpreta constantemente. Pensamos, sin embargo, que la tèsis de Lundahl es muy convincente. Muestra el dilema que se presentaba ante Dessalines entre la creación de la pequeña propiedad que hubiera significado mayor justicia social y el regreso al sistema de plantación que significaba opresión para las grandes masas pero garantizaba mayor seguridad al joven Estado.

La argumentación de Lundahl en el sentido de que fueron las circunstancias económicas y militares las que obligaron a Dessalines a optar por la segunda alternativa nos parece muy sólida. Sin embargo pensamos que, a largo plazo, la creación del Patrimonio Nacional por Dessalines permitió, en mayor grado que en otros países salidos de una dominación colonial similar, el surgimiento de la pequeña propiedad. La concentración de vastas extensiones de tierras en manos del Estado, arrendadas o desocupadas y a menudo débilmente controladas, abrió la posibilidad al campesino sin tierra, al trabajador "prófugo" de las plantaciones, de instalarse, en forma irregular, en dichas tierras, y crear ahí su pequeño fundo. También la compra de tierras adquirió importancia. Paul Moral escribe al respecto:

${ }^{24}$ Pierre-Charles, op.cit., p. 33-34.

25 Moral, op.cit., p. 29.

${ }^{26}$ Leyburn, op.cit., p. 55.

27 Lepkowski, op.cit. vol. 1, p. 91-102.

${ }^{28}$ Lundahl, op.cit. 
... los campesinos independientes aprovecharon en gran medida la puesta en venta de las concesiones individuales y de las tierras del Dominio. 'Hacia 1820 , muchos cultivadores pudieron ya adquirir pequeñas propiedades con sus ahorros.' (Le Propagateur Haitien del 1 de septiembre de 1823). A pesar de que no se pueden dar demasiadas precisiones, parece que la compra de parcelas de plantaciones haya contribuido a expander la pequeña explotación familiar. ${ }^{29}$

\section{d) Politica exterior}

Nos parece importante considerar un último aspecto en nuestra breve presentación de Dessalines: la relación de la revolución triunfante de Haití con el exterior. Queremos mencionar al respecto tres puntos. El primero se refiere a los esfuerzos de Dessalines por establecer relaciones comerciales con naciones neutrales, no comprometidas con Francia. Haiti necesitaba en esos años importar material bélico y manufacturas de diversa índole, ofreciendo a cambio café, maderas y otros productos menores. Son sobre todo Estados Unidos e Inglaterra los países que mostraban interés en ensanchar sus relaciones comerciales con la excolonia francesa. Sin embargo, ante la presión ejercida por Francia y por los propietarios esclavistas del sur, Estados Unidos prohibió en febrero de 1806 todo comercio con Haití.

El embargo, que duró hasta 1809, influyó negativamente en la situación económica haitiana, a pesar de que el vacío fue parcialmente llenado por el comercio con Gran Bretaña, cuyos intereses se aseguraban a través de concesiones aduaneras.

Un segundo punto a considerar es la actitud de Dessalines frente a la permanencia de la esclavitud en las colonias del continente americano y de las Antillas. Por una parte, brindó apoyo material a Francisco de Miranda, cuando éste pasó por Haití en camino a Venezuela, y tanto en Jamaica, como en Cuba y Guadalupe, las autoridades coloniales acusaban al líder haitiano de mandar gente para fomentar la rebelión de los esclavos. Por la otra, renunció expresamente a intervenir en apoyo de los esclavos en las colonias del Caribe. La revolución de Haití sólo puede ser ejemplo para las demás colonias, dice Dessalines en la Proclamación del 28 de abril de 1804 :

... Desafortunados martiniquenses. ¿No puedo correr en vuestro auxilio y romper vuestras cadenas? Desgraciadamente un obstáculo invencible nos separa... Pero quizá una chispa del fuego que nos abrasa brotará en vuestra alma; quizá al ruido de esta conmoción, sobresaltados de vuestro letargo, reivindicaréis, las armas en la mano, vuestros derechos sagrados e imprescriptibles. ${ }^{30}$

Finalmente habria que mencionar que Dessalines comprendia a la isla en su dimensión geopolítica como "una e indivisible". Ante la necesidad de fortalecer la independencia de Haiti, emprendió en febrero de 1805 una expedición a la parte oriental de la isla, -ocupada entonces por Francia, de acuerdo con el Tratado de Basilea concertado en 1795 entre España y Francia-, con el fin de unificar el territorio e impedir todo posible ataque francés proveniente de esa parte de la isla. Dessali-

29 Moral, op.cit., p. 35-36.

${ }^{30}$ Saint-Victor, op.cit., p. 266. 
nes emprendió durante 22 días el cerco a la ciudad de Santo Domingo, sin embargo, la aparición de una flota francesa en este puerto lo hizo declinar su plan y retirarse a Haití, dejando tras de sí las huellas de los enfrentamientos, amenazas o represalias contra la población de la parte española, mismas que originaron entre ésta un profundo resentimiento y odio hacia el cónquistador haitiano.

Los elementos anteriores permiten ver que Dessalines estaba obligado a adoptar una política exterior cautelosa dado el débil sustento económico de la revolución triunfante de la cual era líder, singularidad que tuvo ese proceso en la región. Renunció por ello a expander su régimen hasta el territorio este de la isla y a toda influencia en las colonias esclavistas que rodeaban a Haiti, al mismo tiempo que practicaba una politica comercial abierta y favorable hacia el exterior.

Creemos que nuestro breve análisis - a pesar de no ser exhaustivomuestra que Dessalines no fue ni el mártir que ven algunos ni el político nefasto que critican otros. Su significación para la historia nacional haitiana reside en haber protagonizado el surgimiento de un Estado en condiciones tan adversas y quizá únicas en la historia mundial. A pesar de las múltiples limitaciones (cuyo origen está en su personalidad, su deficiente formación, pero sobre todo en las difíciles condiciones económicas y politicas del momento), Dessalines encabezó con audacia y energía, con su "genio intuitivo y práctico", como dice Gérard PierreCharles, la liberación de la colonia Saint-Domingue y sus primeros pasos como Estado soberano. 